Research Article

\title{
Association of Selected Socio Demographic Variables as Determinants of Quality of Life among Cancer Patients Attending Oncology Department at Sheri-Kashmir Institute of Medical Sciences (SKIMS) Soura Srinagar Kashmir
}

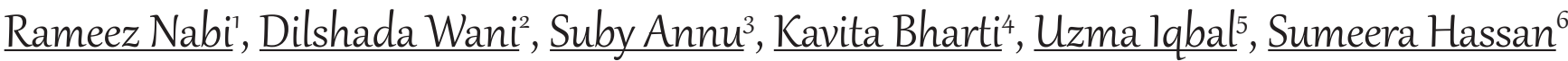 \\ 1,4,5,6M.Sc. Nursing Student, MMINSR, SKIMS Deemed Universit, Jammu \& Kashmir, India. \\ ${ }^{2}$ Principal, ${ }^{3}$ Tutor, MMINSR, Department of Medical Surgical Nursing, SKIMS Deemed University, Jammu \& Kashmir, India. \\ DOI: https://doi.org/10.24321/2454.325X.202017
}

I $\quad \mathbf{N} \quad \mathbf{F} \quad \mathbf{O}$

Corresponding Author:

Rameez Nabi, Nursing Student, MMINSR, SKIMS

Deemed Universit, Jammu \& Kashmir, India.

E-mail Id:

rmzbhtbhat@gmail.com

Orcid Id:

https://orcid.org/0000-0003-1920-5703

How to cite this article:

Nabi R, Wani D, Annu S, Bharti K, Iqbal U, Hassan

S. Association of Selected Socio Demographic Variables as Determinants of Quality of Life among Cancer Patients Attending Oncology Department at Sheri-Kashmir Institute of Medical Sciences (SKIMS) Soura Srinagar Kashmir. Int J Preven Curat Comm Med 2020; 6(4): 28-33.

Date of Submission: 2021-02-19

Date of Acceptance: 2021-03-11
$\begin{array}{llllllll}\mathbf{A} & \mathbf{B} & \mathbf{S} & \mathbf{T} & \mathbf{R} & \mathbf{A} & \mathbf{C} & \mathbf{T}\end{array}$

Background: Cancer is a disease of the cell in which the normal mechanisms for control of growth and proliferation have been altered. It is a harmful lesion capable of invasion of other tissues and metastasis (spread) to distant organs.

Objectives: The objectives of the study were to assess the quality of life among cancer patients and to find the association between the quality of life among cancer patients and their selected socio demographic variables.

Methodology: Descriptive retrospective design was selected to carry out the study. A total of 100 cancer patients were selected for the study by convenience sampling technique. Assessment of quality of life was done by using a self-structured interview schedule and standardized interview schedule (WHOQOL-Bref scale).

Results: The findings of the present study showed that quality of life among cancer patients was found to be average in $84 \%$, good in $10 \%$ and poor in 6\%. The (Mean \pm S.D) QOL was found to be $(51.76 \pm 11.24)$. Significant association was found between $\mathrm{QOL}$ and socio demographic variables i.e. educational qualification $(p=0.004)$ and social support $(p=0.001)$. While, as no significant association was found with other socio demographic variables.

Conclusion: Findings concluded that the QOL was found to be average among cancer patients. Therefore, it is imperative for nurses to include assessment of $\mathrm{QOL}$ in the routine nursing care of these patients with a view to enhance the QOL by appropriate identification and modification of modifiable socio demographic variables such as better access to health care facilities and chemotherapeutic medicines, and better involvement in family and interpersonal relations.

Keywords: Cancer, Quality of Life, Socio Demographic Variables, Social Support 


\section{Introduction}

Cancer is a disease of the cell in which the normal mechanisms for control of growth and proliferation have been altered. It is a harmful lesion capable of invasion of other tissues and metastasis (spread) to distant organs. ${ }^{1}$

Cancer is a genetic disease-that is, it is caused by changes to genes that control the way our cells function, especially how they grow and divide. Genetic changes that cause cancer can be inherited from our parents. They can also arise during a person's lifetime as a result of errors that occur as cells divide or because of damage to DNA caused by certain environmental exposures. Cancer-causing environmental exposures include substances, such as the chemicals in tobacco smoke, and radiation, due to ultraviolet rays from the sun, increasing age, certain viruses, such as Human Papilloma Virus (HPV), lifestyle choices, such as type of diet and level of physical activity. The genetic changes that contribute to cancer tend to affect three main types of genes-proto-oncogenes, tumour suppressor genes, and DNA repair genes. These changes are sometimes called "drivers" of cancer. ${ }^{2}$

Cancer is the main health issue in the community across the world. Globally, cancer is one of the most common causes for morbidity and mortality. The results from the Global Cancer Observatory GLOBOCAN (2012) have shown that 14.1 million new patients were diagnosed with cancer and 8.2 million deaths were due to cancer. Globally, cancers in all forms are causing about $12 \%$ of all deaths. In developed countries, cancer is the second leading cause of death accounting for $21 \%$ of mortality and in developing countries; it ranks third, accounting for $9.5 \%$ of all deaths. ${ }^{3}$

According to Cancer Statistics, 2020: Report from National Cancer Registry Programme India, the projected incidence of patients with cancer in India among males was 679,421 (94.1 per 100,000) and among females 712,758 (103.6 per 100,000 ) for the year 2020. One in 68 males (lung cancer), 1 in 29 females (breast cancer), and 1 in 9 Indians develop cancer during their lifetime (0-74 years of age). The projected five most common cancers in 2020 for males i.e. cancer of (lung, mouth, prostate, tongue, and stomach) constitute $36 \%$ of all cancers and for females i.e. cancer of (breast, cervix uteri, ovary, corpus uteri, and lung) constitute $53 \%$ of all cancers. ${ }^{4}$

Cancer is the second leading cause of death in India, expanding at 11 percent annually. There are 2.25 million cancer cases and every year, new cancer patients registered are over $11,57,294$ and $7,84,821$ deaths are due to cancer(2018). ${ }^{5}$

Quality of life (QOL) is a major concern of patients with terminal cancer. Management of symptoms relieves distress and improves QOL. Quality of life can be measured by using several questionnaires. The holistic treatment of cancer patients requires the health care team to assess what is most important for the individual. Quality of life (QOL) is an important notion in cancer, which varies in individuals. People living with cancer experience a variety of symptoms, which affect their QOL. ${ }^{6}$

The importance of socio demographic factors acting as determinants of quality of life among cancer patients has been reported in several studies. Numerous studies reported that age, gender, level of education, type of treatment, marital status, monthly income, age at cancer diagnosis, cancer type, anxiety and depression are associated with QOL among cancer patients. ${ }^{7}$

A study conducted by Shafaie FS, Mirghafourvand M, Amirzehni J 8 in 2019 on166 breast cancer patients in Tabriz city, Iran. The results revealed that the (mean \pm S.D) of total quality of life score was $(59.1 \pm 17.4)$.Thus, study concluded that quality of life in patients under treatment for breast cancer was moderate; therefore, special attention must be paid by caregivers to improve the quality of life in these patients considering its socio-demographic predictors.

A study conducted by Rukshani D, Kahandawala P et al. ${ }^{9}$ in 2018 on cancer patients in srilanka. The mean overall QOL score was $53.07 \pm 12.68$. Higher QOL was associated with patients who were married, highly educated, employed, had good family support and longer duration of illness. Significantly lower QOL was found in those who were involved in radiotherapy treatments and feeling alone.

The investigator felt the need for a study that could explore the quality of life among cancer patients and their determinants in terms of socio demographic variables like age, gender, marital status, place of residence, educational qualification, economic dependence, type of family, social support, access to health care facilities and availability of chemotherapeutic medicines. This can in turn help to enhance the quality of life in these patients considering their socio demographic predictors.

\section{Methodology}

The researcher selected the patients as per the inclusion criteria and after taking informed consent from Medical Superintendent (SKIMS) and HOD Medical oncology (SKIMS). After seeking permission to conduct study, data was collected from 100 cancer patients at Medical oncology ward and day care of SKIMS and assessment of quality of life was conducted through standardized interview schedule. The data was collected individually from the cancer patients through 09 items of self-structured interview schedule to assess socio demographic variables and 24 items of standardized interview schedule to assess quality of life. Scores are scaled in a positive direction i.e. 1-5 (i.e. higher scores denote higher quality of life). The mean score of 
items within each domain is used to calculate the domain score. Mean scores are then multiplied by 4 in order to make domain scores comparable with the scores used in the WHOQOL-100, and subsequently transformed to a $0-100$ scale. This transformation converts the lowest and highest possible scores to 0 and 100, respectively. Scores between these values represent the percentage of the total possible score achieved.

The quality of life score was categorized into various levels based on the criterion (33 percentile) developed by Abdollahzadeh F et al. ${ }^{10}$ (2009) in his study in 2011. If the score was (67-100), it was considered as good QOL; if the score was (34-66), it was considered as average QOL and if the score was (0-33), it was considered as poor QOL.

\section{Ethical Consideration}

Ethical approval for the current study was obtained from ethical committee of SKIMS Deemed University. Participants were told that they have the right to not participate in the study or to withdraw from the study if they wish at any time. The study subject's privacy was respected, and data were kept confidentially and utilized for study purposes only. Study subjects were asked to read and sign a consent form.

\section{Results}

The Statistical Package for Social Sciences (SPSS) software program was used for data analysis. Frequency distributions were obtained and descriptive statistics were calculated. The distribution of cancer patients according to their socio demographic variables is given in table 1 , Description of QOL scores according to quality of life, physical domain, psychological domain, social domain, and environmental domain is given in table 2 and the association of QOL with socio demographic variables is given in table 3.

Table I.Socio demographic variables of cancer patients

\begin{tabular}{|c|c|c|}
\hline \multicolumn{2}{|c|}{ Socio demographic data } & $\mathbf{f / ( \% )}$ \\
\hline Variables & Opts & \\
\hline \multirow{4}{*}{ Age } & $30-40$ years & $27(27 \%)$ \\
\cline { 2 - 3 } & $41-50$ years & $28(28 \%)$ \\
\cline { 2 - 3 } & $51-60$ years & $23(23 \%)$ \\
\cline { 2 - 3 } & $\geq 61$ years & $22(22 \%)$ \\
\hline \multirow{4}{*}{ Gender } & Male & $52(52 \%)$ \\
\cline { 2 - 3 } & Female & $48(48 \%)$ \\
\hline \multirow{3}{*}{ Residence } & Rural & $58(58 \%)$ \\
\cline { 2 - 3 } & Urban & $42(42 \%)$ \\
\hline \multirow{3}{*}{$\begin{array}{c}\text { Educational } \\
\text { qualification }\end{array}$} & Illiterate & $43(43 \%)$ \\
\cline { 2 - 3 } & Graduation $/ 12$ th & $26(26 \%)$ \\
\cline { 2 - 3 } & Above Graduation & $5(26 \%)$ \\
\hline
\end{tabular}

\begin{tabular}{|c|c|c|}
\hline \multirow{2}{*}{$\begin{array}{c}\text { Economic } \\
\text { dependence }\end{array}$} & Independent & $33(33 \%)$ \\
\cline { 2 - 3 } Type of family & Dependent & $67(67 \%)$ \\
\cline { 2 - 3 } & Nuclear & $57(57 \%)$ \\
\hline \multirow{2}{*}{ Social support } & Joint & $43(43 \%)$ \\
\cline { 2 - 3 } & Available & $86(86 \%)$ \\
\hline \multirow{2}{*}{$\begin{array}{c}\text { Access to health } \\
\text { care facilities }\end{array}$} & Available & $14(14 \%)$ \\
\cline { 2 - 3 } & Not available & $42(58 \%)$ \\
\hline \multirow{2}{*}{$\begin{array}{c}\text { Availability of } \\
\text { chemotherapeutic } \\
\text { medicine }\end{array}$} & $\begin{array}{c}\text { Few medicines you } \\
\text { meed to buy and few } \\
\text { are free }\end{array}$ & $26(26 \%)$ \\
\cline { 2 - 3 } & $\begin{array}{c}\text { Have to buy } \\
\text { and }\end{array}$ & $22(22 \%)$ \\
\hline
\end{tabular}

The results showed in table 3 , represent that there was a significant association between the QOL and socio demographic variables i.e. educational qualification $(p=0.004)$ and social support $(p=0.001)$.While as no significant association was found with other socio demographic variables such as age $(p=0.362)$, gender $(p=0.482)$, place of residence $(p=0.140)$, economic dependence $(p=0.164)$, type of family $(p=0.508)$, access to health care facilities $(p=0.051)$, and availability of chemotherapeutic medicines $(p=0.110)$.

Association of different domains of QOL with socio demographic variables is as follows:

\section{Association of Physical domain of QOL with Socio Demographic Variables}

A significant association between the physical domain of $Q O L$ and socio demographic variables such as age $(p=0.005)$, Social support $(p=0.000)$ and access to health care facilities $(p=0.009)$. While as no significant association was found between the physical domain of quality of life and socio demographic variables such as gender $(p=0.775)$, place of residence $(p=0.406)$, educational qualification $(p=0.107)$, economic dependence $(p=0.257)$, type of family $(p=0.157)$, and availability of chemotherapeutic medicines $(p=0.189)$.

\section{Association of Psychological domain of QOL with Socio Demographic Variables}

A significant association was found between the psychological domain of QOL and socio demographic variables such as educational qualification ( $p=0.027)$, economic dependence $(p=0.011)$, social support $(p=0.004)$ and access to health care facilities $(p=0.003)$. While as no significant association was found with other socio demographic variables such as age $(p=0.289)$, gender $(p=0.187)$, place of residence $(p=0.735)$, type of family $(p=0.697)$ and availability of chemotherapeutic medicines $(p=0.946)$. 
Table 2.Description of QOL scores according to quality of life, physical domain, psychological domain, social domain, and environmental domain

\begin{tabular}{|c|c|c|c|c|c|}
\hline $\begin{array}{c}\text { Descriptive } \\
\text { Statistics }\end{array}$ & $\begin{array}{c}\text { Total score for } \\
\text { QOL }\end{array}$ & $\begin{array}{c}\text { Physical domain } \\
\text { (\%) }\end{array}$ & $\begin{array}{c}\text { Psychological } \\
\text { domain (\%) }\end{array}$ & $\begin{array}{c}\text { Social } \\
\text { domain (\%) }\end{array}$ & $\begin{array}{c}\text { Environmental } \\
\text { domain (\%) }\end{array}$ \\
\hline Mean & 51.76 & 41.22 & 43.85 & 70.42 & 51.57 \\
\hline S.D. & 11.24 & 13.25 & 12.91 & 18.17 & 12.48 \\
\hline Median & 51.54 & 39.29 & 42.18 & 75 & 50 \\
\hline
\end{tabular}

Table 3.Association of QOL with socio demographic variables

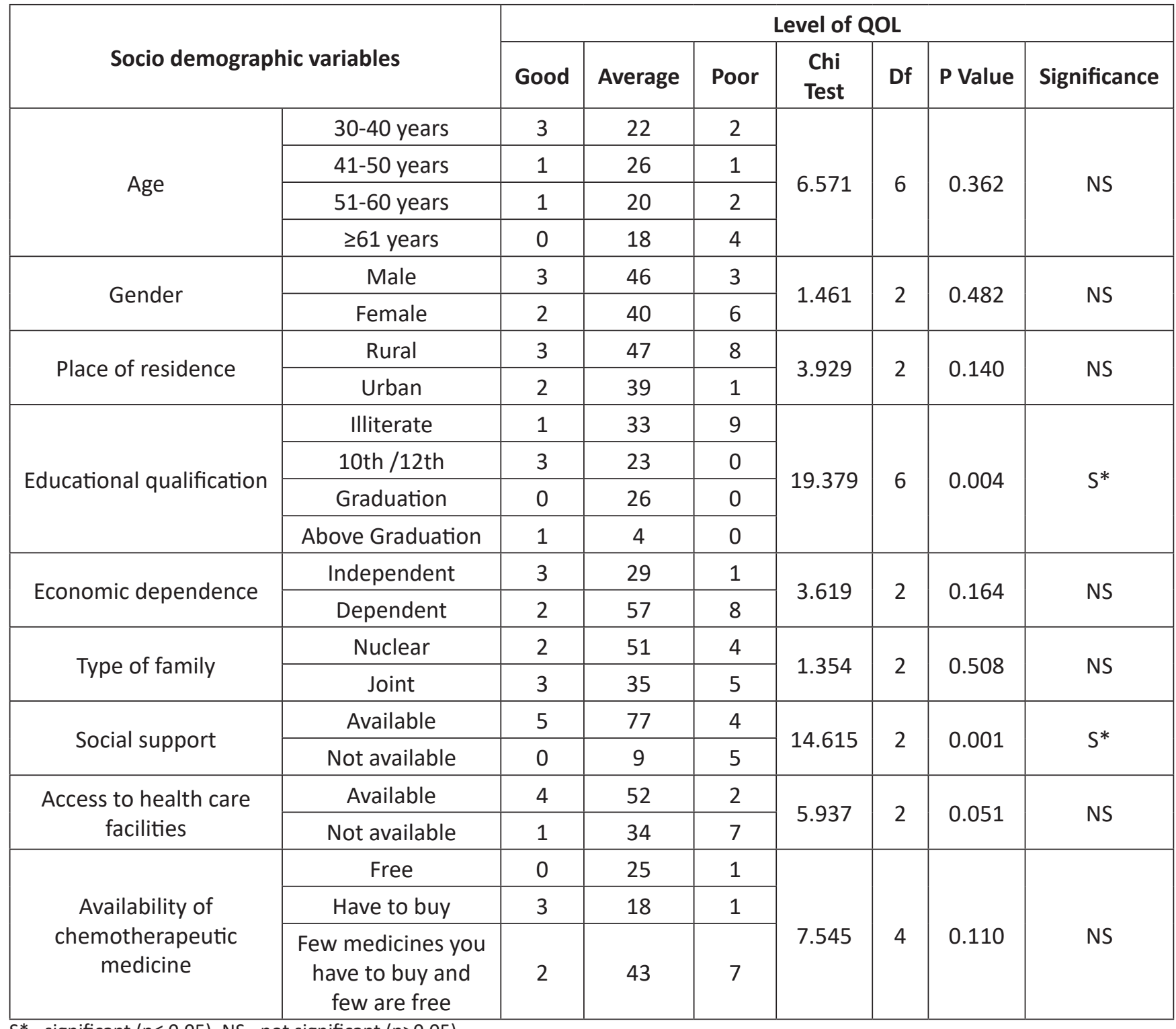

$S^{*}=$ significant $(p \leq 0.05), N S=$ not significant $(p>0.05)$.

\section{Association of Social domain of QOL with Socio Demographic Variables}

A significant association was found between the social domain of QOL and socio demographic variables such as educational qualification ( $p=0.001)$, economic dependence $(p=0.013)$, social support $(p=0.000)$ and access to health care facilities $(p=0.002)$. While as no significant association was found with other socio demographic variables such as age $(p=0.151)$, gender $(p=0.181)$, place of residence $(p=0.296)$, type of family $(p=0.680)$ and availability of chemotherapeutic medicines $(p=0.763)$. 


\section{Association of Environmental domain of QOL with Socio Demographic Variables}

A significant association was found between the environmental domain of QOL and socio demographic variables such as age $(p=0.014)$, place of residence $(p=0.001)$, educational qualification $(p=0.000)$, economic dependence $(p=0.014)$, type of family $(p=0.033)$, social support $(p=0.000)$ and access to health care facilities $(p=0.000)$. While as no significant association was found with other socio demographic variables such as gender $(p=0.766)$, and availability of chemotherapeutic medicines $(p=0.546)$.

\section{Discussion}

The findings of the study revealed that the quality of life among cancer patients was found to be average and a significant association was found between the quality of life and socio demographic variables i.e. educational qualification $(p=0.004)$ and social support $(p=0.001)$. Also different domains of QOL showed significance with different socio demographic variables. The present study demonstrates that social support and educational qualification have significant impact on quality of life among cancer patients.

In a descriptive-analytical cross-sectional conducted by Shafaie FS, Mirghafourvand M, Amirzehni $J^{11} 2019$ ( $n=30$ ) to evaluate the quality of life among 30 females under treatment for breast cancer in Tabriz city, Iran. The results revealed that the (Mean \pm S.D) of total quality of life score was $(59.1 \pm 17.4)$. Thus, study concluded that quality of life in patients under treatment for breast cancer was average.

In a similar analytical cross-sectional study conducted by Chagani P, Parpio Y, Gul R, Jabbar AA 2018 ( $N=150)$ to assess the QOL and its determinants among 150 adult cancer patients undergoing chemotherapy treatment at Tertiary Care Hospital in Karachi, Pakistan. The overall (Mean \pm S.D) of QOL score was $(57.37 \pm 13.11)$. With respect to individual domains, the participants scored best in social domain with a (Mean \pm S.D) score of $(22.33 \pm$ 3.42). Whereas individuals had lower (Mean \pm S.D) scores in physical domain and emotional that is, (10.41 \pm 5.32$)$, and $(10.32 \pm 4.95)$ respectively.

In a descriptive cross sectional study conducted by Rukshani D, Kahandawala P, Jayawardana K, Karunarathne D, Galgamuwa LS, Kumara C et al. ${ }^{13} 2018$ ( $\left.N=167\right)$ to evaluate factors associated with the quality of life among cancer patients in Srilanka, the overall (Mean \pm S.D) QOL score was (53.07 \pm 12.68$)$. Higher QOL was associated with patients who were higher educated $(p=0.004)$, and had good family support $(p=0.001)$.

In another similar cross-sectional study conducted by Hassen AM, Gizaw M, ${ }^{14} 2019$ ( $\left.n=404\right)$ to study quality of life among breast cancer patients at Tikur Anbessa specialized hospital, Ethiopia. The average quality of life score of patients with breast cancer under chemotherapy treatment was $(52.98 \pm 25.61)$. Higher educational qualification $(p=$ 0.041 ) was significantly associated with improved (better) quality of life.

These findings provide a scientific basis to develop a comprehensive program that incorporates these factors, especially social support, to improve the QOL among cancer patients. Families caring for cancer patients, recently diagnosed, singly living, less educated and not formally employed patients need educational support, counselling and awareness programs on psychotherapeutic aspects to cope up with and support to enhance psychosocial and physical aspects of patients. The findings emphasize the importance for improving cancer care programs about quality of life of patients in Kashmir. Future research should focus on the improvement of quality of life among cancer patients considering different socio demographic variables.

\section{Conclusion}

Findings concluded that the QOL was found to be average among cancer patients. Therefore, it is imperative for nurses to include assessment of $\mathrm{QO}$ in the routine nursing care of these patients with a view to enhance the QOL by appropriate identification and modification of modifiable socio demographic variables such as better access to health care facilities and chemotherapeutic medicines, and better involvement in family and interpersonal relations.

\section{Conflict of Interest: None}

\section{References}

1. Joyce M. Black, Jane Hokanson Hawks, Medical surgical nursing-clinical management for positive outcomes. 8th edition.P:250.

2. National cancer institute. Available from: https://www. cancer.gov/about-cancer.

3. Ferlay J, Soerjomataram I, Dikshit R, Eser S, Mathers $\mathrm{C}$, Rebelo $\mathrm{M}$ et al. Cancer incidence and mortality worldwide: sources, methods and major patterns in GLOBOCAN 2012. Int J Cancer 2015; 136(5): 35986. Available from: https://www.who.int/cancer/ PRGlobocanFinal.pdf

4. Mathur P, Sathishkumar K, Chaturvedi M, Das P, Sudarshan KL, Santhappan $S$ et al. Cancer statistics, 2020: Report from national cancer registry Programme, India. JCO Global oncology [Internet]. 2020 Sep [cited 2020 Nov 22];(6):1063-75. Available from: https:// ascopub s.org/doi /10.1200/GO.20. 00122.

5. National Institute of cancer Prevention and Research, Cancer statistics 2018.Available from: cancerindia.org. in/cancer-statistics/

6. Swamy P. A study to determine quality of 
life in cancer patients. International journal of Oncological Nursing. Volume 1.. Available from: http://citeseerx.ist.psu.edu/viewdoc/ download?doi=10.1.1.838.9751\&rep=rep1\&type=pdf.

7. Akhtari-Zavare $M$, Mohd-Sidik S, Periasamy U, Rampal L, Fadhilah SI, Mahmud R. Determinants of quality of life among Malaysian cancer patients: a cross-sectional study. Health Qual Life Outcomes [Internet]. 2018 Dec [cited 2020 Nov 22]; 16(1): 163. Available from: https ://pubmed .ncbi .nlm .nih .gov/ 30103759/

8. Shafaie FS, Mirghafourvand M, Amirzehni J. Predictors of quality of life in patients with breast cancer. Indian J Palliat Care 2019;25:73-8. Available from: https://www. jpalliativecare.com/text.asp?2019/25/1/73/251067

9. Rukshani D, Kahandawala P, Jayawardana K, Karunarathne D, Galgamuwa LS, Kumara C et al. Factors associated with quality of life among cancer patients in Sri Lanka. Int J Community Med Public Health [Internet]. 2018 Jun 22 [cited 2020 Nov 22];5(7):2705. Available from: http:/ /www. ijcmph. com/index.php/ijcmph/ article/view/2962

10. Abdollahzadeh F, Aghahossini SS, Rahmani A, Asvadi Kermani I. Quality of Life in cancer patients and its related factors. Journal of Caring Sciences [Internet]. 2012 [cited 2020 Nov 22]; Available from: http://journals. tbzmed.ac.ir/JCS/Abstract/JCS_278_20120528141426

11. Shafaie FS, Mirghafourvand M, Amirzehni J. Predictors of quality of life in patients with breast cancer. Indian J Palliat Care 2019;25:73-8.Available from: https://www. jpalliativecare.com/text.asp?2019/25/1/73/251067

12. Chagani P, Parpio Y, Gul R, Jabbar A. Quality of life and its determinants in adult cancer patients undergoing chemotherapy treatment in Pakistan. Asia Pac J Oncol Nurs [Internet]. 2017 [cited 2020 Nov 22];4(2):140. Available from: http://www.apjon.org/ text.asp?2017/4/2/140/204499

13. Rukshani D, Kahandawala P, Jayawardana K, Karunarathne D, Galgamuwa LS, Kumara C, et al. Factors associated with quality of life among cancer patients in Sri Lanka. Int $J$ Community Med Public Health [Internet]. 2018 Jun 22 [cited 2020 Nov 22];5(7):2705. Available from: http:/ /www. ijcmph. com/index.php/ijcmph/ article/view/2962

14. Hassen AM, Taye G, Gizaw M, Hussien FM. Quality of life and associated factors among patients with breast cancer under chemotherapy at Tikur Anbessa specialized hospital, Addis Ababa, Ethiopia. Ahmad A, editor. PLOS ONE [Internet]. 2019 Sep 20 [cited 2020 Nov 22];14(9):e0222629. Available from: https:// dx.plos.org/10.1371/journal.pone.0222629 